\title{
DESAFIOS DO SINDICALISMO NA SOCIEDADE GLOBALIZADA
}

\author{
Giovanni Olsson ${ }^{1}$ \\ Janaina Eloise Renk ${ }^{2}$
}

\section{Resumo}

Este estudo objetiva a compreensão dos desafios da atuação dos sindicatos na sociedade contemporânea na era da globalização. $\mathrm{O}$ trabalho analisa o fenômeno da globalização e seus impactos no mundo do trabalho, com as profundas transformações do capitalismo avançado em toda a sociedade internacional. Em todo o mundo, as formas de organização da produção e do trabalho mudaram profundamente, criando uma realidade até então inédita. Além disso, e como exemplo, o estudo investiga a representação dos sindicatos e os instrumentos coletivos utilizados por eles no direito brasileiro. O Brasil possui um modelo sindical que não admite a pluralidade sindical e permanece inalterado ao longo dos últimos mais de 70 anos, em descompasso com as grandes alterações econômicas e sociais do início do século XXI. O trabalho, por fim, também analisa as tendências do protagonismo dos sindicatos na atual sociedade globalizada. Os sindicatos constituem importantes atores na afirmação de direitos políticos, sociais e econômicos das categorias que eles representam. A principal conclusão do estudo é de que a maior efetividade da atuação dos sindicatos na sociedade globalizada envolve a construção de um novo paradigma, fundado em democracia, pluralidade e liberdade sindical, reconhecidos como direitos universais pela Organização Internacional do Trabalho. A metodologia utilizada neste artigo consiste no método dedutivo, e a pesquisa é caráter qualitativo com base bibliográfica.

Palavras-chave: Sindicato; Globalização; Sociedade Internacional.

\section{INTRODUÇÃO}

Este estudo enfrenta introdutoriamente os desafios do sindicalismo na sociedade globalizada e o papel do sindicato, que não é meramente representativo dos interesses individuais e coletivos de seus associados, mas sim de toda a categoria.

Durante o estudo, pode-se verificar a importância do sindicalismo na expansão do sistema capitalista em razão do fenômeno da globalização, que foi um dos principais fatores econômicos que revelaram profundas mudanças entre os mais e menos favorecidos social e economicamente, principalmente entre as relações jurídicas

\footnotetext{
${ }^{1}$ Doutor em Direito (UFSC). Vice-Líder do Grupo de Pesquisa Relações Internacionais, Direito e Poder (CNPQ). Professor Permanente do Programa de Mestrado em Direito da Universidade Comunitária Regional na linha Atores Internacionais (UNOSC). E-mail: golsson71@gmail.com

${ }^{2}$ Pesquisadora. E-mail: janarenk@unochapeco.edu.br
} 
entre empregador e trabalhador.

Esta pesquisa tem por objetivo geral identificar os desafios dos sindicatos na sociedade globalizada e a efetividade das suas ações como representante dos interesses dos trabalhadores. Esse objetivo geral destaca-se por explicar os principais desafios do sindicalismo no contexto do mundo do trabalho agora globalizado.

No Brasil, como exemplo, há uma série de direitos trabalhistas, outorgados e garantidos por norma estatal. Porém, a política mundial e a globalização econômica estão ensejando questionamentos quanto a uma alegada rigidez das normas de proteção ao trabalho, e emergem discursos a favor da flexibilização e desregulamentação das normas trabalhistas. Essas ideias são justificadas na suposta representação sindical, propugnando-se que os direitos trabalhistas sejam estabelecidos por meio de negociações coletivas.

Outrossim, a unicidade sindical presente no nosso ordenamento jurídico enseja a discussão quanto à legitimidade do sindicato como representante da categoria, inclusive porque, independentemente de ser sindicalizado, o trabalhador contribui, compulsoriamente, no custeio das entidades sindicais.

Por isso, justifica-se o recorte desta pesquisa para identificar os desafios do sindicalismo na sociedade globalizada, analisando a emergência do sindicalismo como movimento internacional, englobando, também, o direito sindical no país, bem como a efetiva participação do integrante da categoria na vida sindical e, por fim, o futuro do sindicalismo no mundo globalizado.

Em síntese, e com o presente trabalho, pretende-se apresentar uma contribuição ao estudo do tema do sindicalismo na sociedade contemporânea globalizada, tratando dos principais desafios que se apresentam para o futuro do século XXI.

\section{A GLOBALIZAÇÃO E SEUS IMPACTOS NO MUNDO DO TRABALHO}

A sociedade atual vive a era da globalização, fenômeno que tem influência em quase todos os acontecimentos políticos, econômicos e sociais dos últimos tempos. Esse novo processo está ligado à expansão do modo de produção capitalista e vem sendo utilizado para camuflar as políticas neoliberais pelo mundo (ALBUQUERQUE, 2006, p. 23).

No Brasil, a semente do neoliberalismo foi plantada com os governos de Fernando Collor de Mello e Fernando Henrique Cardoso, com amplo apoio de grupos da mídia e de instituições financeiras de atuação global. Assim, inicia-se o processo de criação de uma nova supremacia burguesa no país, calcada nas concepções e propostas políticas neoliberais (BOITO JUNIOR, p. 80).

A globalização caracteriza-se pelo acelerado fluxo de informações entre todos os países e atinge as 
empresas, as pessoas e a sociedade como um todo, bem como pelas rápidas transações econômicas de mercadorias, capitais e aplicações financeiras que ultrapassam as fronteiras nacionais e, ainda, pela difusão dos valores políticos e morais em escala universal. Assim, a globalização espalha-se pelo mundo praticamente como se não houvesse nenhuma distância ou barreira geográfica. Como tal, ela repercute nas notícias difundidas internacionalmente, na economia e nas sociedades cada vez mais influenciadas pelas produções de corporações transnacionais, pela entrada de capitais na Bolsa e pelo uso de novas tecnologias e bens de consumo importados (BARBOSA, 2003).

Esse fenômeno atinge a sociedade do mundo todo, e alguns Estados entendem que atrair capital de investimento de empresas transnacionaispoderá por si mesmo gerar mais empregos. Outros visualizam recursos públicos com linhas de crédito mais favoráveis como meros instrumentos de troca de favores para redução de cláusulas sociais e econômicas vigentes nas relações de trabalho. Desse modo, o Estado fica sem controle e autonomia em relação às políticas públicas de trabalho, pelo fato de as empresas transnacionais terem grande poder sobre a economia, e, logo, sobre os destinos da arrecadação de tributos e a geração de trabalho e renda (OLSSON, 2014, p. 597).

A globalização dissemina o capital financeiro para além dos limites territoriais dos Estados-nação, influenciando na política, na cultura e na legislação, criando ou extinguindo empregos, determinando novas demandas por tecnologia e matéria-prima, novos mercados, bem como repercutindo ainda sobre outras atividades já existentes nas localidades. Essas práticas transnacionais operam sobre a inclinação política da relação entre capital e trabalho, interagindo diretamente com as organizações políticas e sindicais, manipulando-as, difundindo a idéia de que a atividade doméstica não possui capacidade de concorrer-e que a única forma para se manter é se moldar à economia global.

Esse fenômeno propõe o desenvolvimento das nações por meio da autorregulação de mercado, mas suas consequências são graves em termos macroeconômicos, como por exemplo a desigualdade, a seletividade e a exclusão social, resultados de um crescimento puramente econômico acelerado e a qualquer custo (ALBUQUERQUE, 2006, p. 23).

A globalização, assim, é um processo multidimensional que explica a atual sociedade contemporânea, e, por intermédio dele, é possível compreender a complexidade e a intensidade das relações internacionais.

Nessa feição marca da mente financeirizada da expansão capitalista, a globalização é um fenômeno recente na história, mas abrangente e muito dinâmico como um processo em andamento. $\mathrm{O}$ marco inicial exato desse fenômeno é um tema controverso, contudo, os autores de uma forma geral chegam a mesma conclusão: a de que esse fenômeno está ligado ao crescimento intensivo e extensivo do capitalismo em torno do mundo, assim 
como a transformação quantitativa e qualitativa do sistema capitalista como modo de produção e processo civilizatório, com a expansão do capitalismo pelo mundo. Há, também, relação com o modo de produção dessa era capitalista, pela crise do padrão monetário no mundo e a crise do petróleo em 1970, exaurindo o potencial do modelo de produção da época (ALBUQUERQUE, 2006, p. 23-24).

A globalização, como dito, é um processo multidimensional, resultado da reconfiguração da sociedade capitalista atual. O desenvolvimento da economia tem suma importância em termos de globalização e como fator de transformação da nova realidade do mundo do trabalho. A globalização também pode ser entendida como a reunião de processos interligados, como autonomia da economia frente à política; novas estruturas de produção em larga escala e com alcance global; mudanças na competitividade entre as indústrias e continentes; desenvolvimento do padrão de comércio internacional; descentralização de formas de política e de capitalismo; padronização de práticas comerciais em nível mundial; unificação dos espaços de reprodução social e aumento da imigração (ALBUQUERQUE, 2006, p. 24-25).

Todas essas transformações e acontecimentos históricos, principalmente pelo desenvolvimento da globalização, possuem significativa influência no mundo do trabalho. $\mathrm{O}$ trabalho sempre foi uma condição de existência do ser humano. Assim, os homens vivem em sociedade e se relacionam em forma de cooperação e intercâmbio, dando origem a relações de trabalho e renda e formando forças produtivas, e criando assim vários modos de produção (ALBUQUERQUE, 2006, p. 25).

As então corporações multinacionais originadas nos países industrializados foram aumentando o grau de concorrência entre si, possibilitando grandes avanços das tecnologias de produção na busca pela redução dos custos de produção e crescimento dos lucros no mercado internacional. Com o pós-Segunda Guerra, várias tecnologias se tornaram populares, como a robótica e os computadores. Por meio dessas novas invenções, o acesso às informações tornou-se mais célere, com um consequente aumento da produtividade nas fábricas, assim como com avanços consideráveis dos transportes nas vias aéreas, terrestres e aquáticas, ocasionando maior circulação de bens e de pessoas (SENE, 2003, p. 41).

A redução dos custos de transporte proporcionou também sua massificação e utilização em larga escala, encurtando distâncias e aproximando não apenas pessoas, mas também unidades de produção e mercados consumidores. As corporações, até então multinacionais, assumiram o perfil de transnacionais, ao desconectaremse de seus Estados de origem para se vincularem exclusivamente aos interesses de seus acionistas, agora tão globalmente dispersos como seus próprios parques produtivos, produtos customizados e mercados consumidores.

A globalização produtiva e financeira, associada à competitividade desregulada (ou pretensamente 
autorregulada), produz limitação ou até abandono da ação pública para normatização das relações econômicas individuais, setoriais, nacionais e internacionais. Tudo isso constitui tendência da geração de políticas de desregulamentação do mercado de trabalho, em especial as direcionadas ao controle e à redução de custos salariais (POCHMANN, 2002, p. 27-28).

O mundo do trabalho também é fortemente atingido pela globalização, por meio das drásticas transformações dos processos de reestruturação produtiva, influenciando no modelo das relações de trabalho. É muito importante priorizar a cidadania e a dignidade da pessoa, valores fundamentais, ao não se admitir que novas tecnologias sejam utilizadas para provocar desemprego, aumentando a desigualdade e as distâncias sociais dentro das sociedades e entre os povos (PEREIRA, 2004, p. 14).

Conforme atenta Albuquerque (2006, p. 32-33), o uso da ciência como técnica de produção deu origem à Segunda Revolução Industrial. Os avanços da ciência, até então universalmente compartilhados, converteram-se em técnicas produtivas direcionadas para a otimização de processos de produção e foram progressivamente capturadas pela apropriação privada dos conhecimentos em patentes.

No fim do século XIX, Frederick Taylor criou a racionalização do trabalho com base no método separatista, ao observar a forma de atuação dos trabalhadores de uma metalúrgica norte-americana, para que não houvesse desperdício de tempo com movimentos desnecessários. Assim, Taylor dividiu as tarefas, nas quais cada operário limitava-se a gestos repetitivos e iguais, sem necessidade de qualificação profissional e nem a participação em todo o processo de produção ou sequer conhecimento deste.

Henry Ford, proprietário de uma indústria automobilística, por sua vez, criou um método de produção que incorporou as mesmas técnicas de gerenciamento taylorista. Esse novo método era voltado a atender o aumento da demanda por meio da produção em massa, com redução de custos de produção e consequente redução no preço final do produto (ALBUQUERQUE, 2006, p. 33): produtos idênticos, com processos produtivos especifica e fracionadamente repetidos.

Conforme Antunes (2005, p. 37-38), o processo fordista de produção foi introduzido por toda a indústria automobilística dos EUA e, após, em quase todos os principais países capitalistas.

Esse novo modo de produção foi considerado a forma mais avançada de racionalização capitalista do processo de trabalho por praticamente todo o século XX, mas que, por volta dos anos 60 a 70, começou a dar indícios de exaustão embora não tenha sido totalmente superado em vários segmentos até hoje.

Nesse período, houve a crise do petróleo, aliada à crise e insegurança financeira, somadas a uma série de conseqüências como inflação descontrolada, altos níveis de desemprego, elevação dos movimentos trabalhistas, pressão dos sindicatos e confronto entre política econômica e política social, e, por conseguinte, crescimento das 
desigualdades. Tudo isso impactou a teoria do keynesianismo, por acreditar que a intervenção do Estado na economia era a causa da crise instaurada, ao impossibilitar os investimentos e crescimentos econômicos autorregulados. Assim, surgiu a ideologia do neoliberalismo, que defendia medidas de privatização e desregulamentação dos mercados financeiros, estimulando o comércio em nível mundial de acordo com a "mão invisível" do mercado. O capitalismo neoliberal elevou a racionalidade produtiva e organizacional ao plano global, bem como aprofundou a conversão das ciências em meras técnicas de produção (ALBUQUERQUE, 2006, p. 33).

Com essa crise da década de 1970, ocorre um processo de reestruturação capitalista nos EUA, Japão e Europa Ocidental, dando margem ao surgimento de um novo conjunto de organização produtiva que afeta o mundo do trabalho organizado em meio à Terceira Revolução Industrial. A partir da transformação das redes telemáticas e informacionais, baseadas na globalização e no sócio-metabolismo do capital através do trabalho, é que se difundiram as novas feições do mundo do trabalho. Por meio desses processos de reestruturação produtiva, se desenvolveram os meios de produção capitalista-industrial. No século XX, a nova estruturação produtiva é baseada nas inovações fordistas-tayloristas, com grandes mudanças tecnológicas na estrutura da produção de mercadorias em vários setores da indústria (ALVES, 2007, p. 155).

Essas inovações tecnológicas foram inseridas nas indústrias, alterando as relações de trabalho e de produção de capital, o que originou novas formas de organização do trabalho, como o modelo de especialização flexível e o toyotismo, que agora mais adaptáveis para adequar o ritmo e o volume da produção às demandas e especificidades do mercado (ALBUQUERQUE, 2006, p. 37).

O modelo de especialização flexível, criado por Charles e Michel Piore, vem com a experiência da chamada “Terceira Itália”, conjuntamente ao desenvolvimento tecnológico e uma desconcentração produtiva por meio de pequenas empresas artesanais. Esse novo modelo de produção repudia a produção em massa, atendo-se a um trabalho mais flexível e não alienado (ANTUNES, 2006, p. 25).

Esse modelo, não obstante, exige que os trabalhadores sejam polivalentes, chegando a operarem várias maquinas concomitantemente, com o "gerenciamento por tensão", inicialmente por meio do sistema de luzes. Com a alteração do modo de produção, modificam-se também as relações de trabalho. No toyotismo, a força de trabalho é muito explorada, evitando-se a todo custo a ociosidade no trabalho. Se o mercado está em alta, contratam-se operários temporários ou os contratados são obrigados a fazer hora extra (ALBUQUERQUE, 2006, p. 39-41).

Paradoxalmente, o surgimento do sindicalismo de empresa foi de suma importância para o modo de produção toyotista. Nesse período, as empresas precisavam que o novo modo de produção fosse aceito pelos 
trabalhadores. Assim, a Toyota moldou os sindicatos segundo seus interesses e garantiu emprego vitalício aos seus empregados.

Esse sindicato, então, é manipulado pelas empresas, de modo que as lutas entre operários e capitalistas foram trocadas por uma forma de cooperação entre estes: "através da manipulação do sindicato, o operário acredita que o aumento do lucro da empresa se converterá em vantagens para si, iludido com o emprego vitalício, pela qualificação e remuneração" (ALBUQUERQUE, 2006, p. 41-42).

Todas essas transformações no modo de produção acabam refletindo no mundo do trabalho sob a forma de desregulamentação dos direitos do trabalho e assim como no aumento da desintegração da classe trabalhadora. Dessas transformações, decorrem a precarização e a terceirização da força de trabalho, vindo a contribuir, no fundo, com o desmantelamento do sindicalismo de classe (ANTUNES, 2005, p. 52).

Segundo Antunes (2006, p. 38-39), o modelo japonês de produção tem apresentado "potencial universalizante" e impactos negativos no mundo do trabalho, ao afirmar que:

A consequência mais evidente é o distanciamento pleno de qualquer alternativa para além do capital, à medida que se adota e postula uma ótica de mercado, da produtividade, das empresas, não levando sequer em conta, com a devida seriedade, entre tantos elementos tão graves e prementes como, por exemplo, a questão do desemprego estrutural [...]. Desemprego este que é resultado dessas transformações no processo produtivo, e que se encontra, no modelo japonês, no toyotismo, aquele que tem causado maior impacto, na ordem mundializada e globalizada do capital (grifo do autor).

Para o autor, essas mudanças, de uma forma ou de outra, atuam com maior ou menor intensidade em cada país, conforme sua cultura, política e economia, de modo a atingir o operário tradicional, transformando o "ser do trabalho" e o universo da consciência da subjetividade do trabalho e suas formas de representação. Assim, os sindicatos, acuados, ficam apenas na defensiva, atuando como "sindicalismo de participação e de negociação", sem atingir seu papel com uma atuação global de emancipação do trabalho, promovendo apenas ações limitadas dentro dos valores do mercado e do capital e de sua lógica (ANTUNES, 2006, p. 42-43).

Os sindicatos são entidades com capacidade para criar "um novo projeto para a sociedade onde a cidadania esteja identificada com a emancipação política e social do trabalhador, no qual o sindicato assuma um papel crítico a interagir sobre os destinos da sociedade com outros segmentos populares rumo à democracia [...]", com base na liberdade e na solidariedade (PEREIRA, 2004, p. 70).

A fragmentação dos trabalhadores é uma catástrofe para os sindicatos, porque é quase impossível travar uma luta contra o capitalismo que "evita deliberadamente que a circulação de capitais e mercadorias se reflita numa livre circulação de pessoas", remetendo a um problema da contemporaneidade: o desemprego estrutural (PEREIRA, 2004, p. 26-28). Desse modo, acredita-se que a mobilização dos trabalhadores implicaria no fortalecimento das entidades sindicais como representantes na luta contra o desemprego e a precariedade do 
trabalho. Nesse contexto, um dos maiores óbices à mobilização da sociedade contemporânea é o individualismo, que deve ser afastado para que se permita a luta ao combate contra os meios de precarização e desvalorização do trabalhador como ser social.

Atualmente, o capitalismo contemporâneo é caracterizado pela desproletarização do trabalho industrial tradicional, juntamente com a precarização do trabalho através da subcontratação e pela terceirização, atrelados à economia informal.

\section{A REPRESENTAÇÃO SINDICAL E OS INSTRUMENTOS COLETIVOS}

Em relação à representação da categoria, os sistemas sindicais dividem-se entre os modelos da unicidade e da pluralidade sindical. Segundo Nascimento (2003, p. 159), o mais adequado destes sistemas é aquele que disponibiliza aos interessados a escolha do tipo de associação que desejam constituir, sem qualquer proibição ou imposição de limite por parte do Estado que venha a prejudicar essa escolha.

O sistema da unicidade sindical proíbe, por meio de lei, a criação de mais de um sindicato na mesma base territorial de atuação, e inclusive proíbe a criação de mais de um sindicato da mesma categoria.

No sistema da pluralidade sindical, é possível a criação de mais de um sindicato na mesma base territorial, representando pessoas ou atividades que tenham um interesse coletivo em comum. Desse sistema, decorre a pluralidade orgânica e a unidade de ação, que tratam da possibilidade de existência de mais de um sindicato representativo e concorrente, de modo que, se estes vierem a se unir numa atuação conjunta, ocorre a unidade de ação, mesmo que organicamente sejam sindicatos isolados. Existe também um misto entre pluralidade e unicidade, como, por exemplo, quando na cúpula existem diversas centrais sindicais, mas na categoria apenas é permitido um sindicato na mesma base territorial (NASCIMENTO, 2003, p. 162-163).

No sistema brasileiro,que pode servir de exemplo para compreender os modelos de representação sindical e seus instrumentos, vige o princípio da unicidade sindical em nível confederativo, ou seja, dos sindicatos à confederação de categoria. Desse modo, no Brasil, é proibida, por lei, a criação de mais de um sindicato na mesma base territorial dentro da mesma esfera de representatividade (NASCIMENTO, 2003, p. 164).

No Brasil, as negociações coletivas são simétricas ao sistema da unicidade adotado: o mesmo sindicato da categoria é parte legítima para negociar pela categoria e pelos trabalhadores da empresa. Desse modo, segundo Nascimento, existem dois níveis de negociação coletiva, ou seja, o nível de categoria e o de empresa, sendo que, para ambos, é o mesmo sindicato que os representa. Assim, conforme o autor: "o mesmo sindicato que tem legitimidade para negociar as convenções coletivas aplicáveis a toda a categoria também a terá para negociar 
acordos coletivos representando unicamente os empregados da categoria que trabalhem em uma empresa" (2003, p. 166).

Após a Convenção n87 da Organização Internacional do Trabalho, as discussões em prol da adoção do sistema da pluralidade sindical ganham mais força. Essa normativa prevê a liberdade de organização dos trabalhadores e considera serem a determinação de territorialidade e a proibição da criação de mais de uma entidade sindical para uma mesma base territorial afrontas ao princípio da liberdade sindical.

No entendimento de Russomano (2000, p. 74-75), a pluralidade sindical, diferente da unicidade, permite que esta categoria profissional ou econômica esteja, no mesmo lugar e ao mesmo tempo, associada em torno do sindicato existente ou dividida em diversos sindicatos de mesma natureza. Já no regime da unicidade sindical, a liberdade do trabalhador é mínima e deixa ao trabalhador apenas uma opção: associar-se ou não ao sindicato único. Conforme o autor, com a pluralidade sindical, o trabalhador tem o direito de escolher, dentre os sindicatos existentes, aquele que se aproxima mais de seus ideais e anseios. Mesmo no sistema do pluralismo sindical, os interessados podem, de forma convencional, unir-se em um só sindicato. Essa opção de sindicato único resulta de um fenômeno natural, ou seja, do "movimento espontâneo das opiniões trabalhistas", dando a esse sindicato uma força maior de ação e reação, ao contrário da imposição de um sindicato único, que "se torna presa fácil das pressões estranhas ao sindicalismo ou dos grupos políticos", podendo ser corrompido por partidos políticos.

Nesse contexto, conclui-se que o melhor sistema contemporâneo é o da pluralidade sindical, não como imposição legal, mas como opção, de modo que os diversos sindicatos criados na mesma base territorial possam se unir, formando uma unidade na busca de uma maior representatividade.

O Brasil, porém, é um dos poucos países que não ratificou a Convenção n87, evige em nosso ordenamento o sistema da unicidade sindical, que está sendo discutido, por exemplo, pela Proposta de Emenda à Constituição - PEC n³69/2005, em tramitação no Congresso Nacional, que busca dar nova redação aos arts. $8^{\circ}$, 11, 37 e 114 da Constituição. Nessa proposta, pretende-se: instituir a contribuição de negociação coletiva; a representação sindical nos locais de trabalho e a negociação coletiva para os servidores da Administração Pública; acabar com a unicidade sindical; incentivar a arbitragem para solução dos conflitos trabalhistas; e ampliar o alcance da substituição processual, podendo os sindicatos defender em juízo os direitos individuais homogêneos. A proposta da reforma sindical está apoiada no objetivo de fortalecer as entidades representativas.

Esses instrumentos coletivos de negociação tiveram origem na Europa em virtude da industrialização dos países europeus ocidentais, pela exploração técnica e das campanhas operárias originárias das grandes concentrações de trabalhadores. 
Em princípio, o Estado posicionava-se com cautela, insurgindo quanto à possibilidade de negociação direta entre empresários e trabalhadores através das entidades sindicais. $\mathrm{O}$ Estado temia essas normativas em detrimento do surgimento de obrigações, não só entre as partes da negociação, mas também regras de conduta a serem respeitadas na prática de outros atores jurídicos trabalhistas (RUSSOMANO, 2000, p. 144).

Mesmo que o Estado negasse a legitimidade e a eficácia jurídica desses convênios, perém, não podiam ser contestados em razão das vantagens práticas que geravam. Era uma nova forma de conciliação entre as partes, "útil a paz social". Nos conflitos de maior complexidade, o acordo pactuado diretamente entre as partes tinha o intuito de remediar o conflito imediatamente, e, em alguns casos, até mesmo solucionava o conflito. Por meio das convenções coletivas, os trabalhadores representados por seus sindicatos negociavam, em pé de igualdade com seus empregadores, as cláusulas de uma nova convenção, o que demonstra a legitimidade e a representação sindical (RUSSOMANO, 2000, p. 143-144).

Na América Latina, na Ásia e na África, onde a economia era baseada na agricultura, os instrumentos coletivos apenas ganharam força com o desenvolvimento econômico ocorrido a partir da industrialização, muitos anos depois da Europa. O desenvolvimento econômico, em sentido globalista, favorece o desenvolvimento industrial que, por sua vez, contribui para o desenvolvimento do sindicalismo, tornando o sindicato mais forte, atuante e ciente de sua importância nas negociações coletivas (RUSSOMANO, 2000, p. 145).

Segundo Delgado (2013, p. 1405-1406), atualmente, os métodos de solução de conflitos interindividuais e sociais estão divididos em três grupos: autotutela, heterocomposição e autocomposição. A negociação coletiva compõe o grupo da autocomposição, que ocorre quando as próprias partes resolvem o conflito, sem a participação de outros agentes no processo de solução do litígio. A heterocomposiçãoocorre quando há intervenção de um terceiro, que não é parte no litígio, tendo controle sobre a dinâmica de solução do conflito, através das modalidades da jurisdição, arbitragem, conciliação e mediação. Já na modalidade da autotutela, uma das partes, de forma unilateral, impõe sua vontade à outra parte segundo seu próprio interesse.

Os instrumentos coletivos, por sua vez, dividem-se em negociais e judiciais. Os instrumentos coletivos negociais são compostos pelo acordo coletivo, convenção coletiva e contrato coletivo. O judicial é formado basicamente pela ação de dissídio coletivo.

Segundo Nascimento (2004, p. 1114), as negociações em nível de categoria dão ensejo às convenções coletivas de trabalho, aplicáveis a todos os empregados e empregadores, sócios ou não dos sindicatos, do setor de atividade no qual a negociação se der. Já as negociações em nível de empresa resultam nos acordos coletivos aplicados apenas às empresas que participam da negociação.

A Organização Internacional do Trabalho criou a Convenção no 154 , que se refere a promoção da 
negociação coletiva, em Genebra, no ano de 1981. A normativa esclarece, em seu art. 2º que a negociação coletiva atinge todas as negociações entre um empregador, um grupo de empregadores ou uma ou mais organizações de empregadores, e uma ou mais organizações de trabalhadores, a fim de determinar as condições de trabalho e de emprego; regular as relações entre empregadores e trabalhadores; e disciplinar as relações entre os empregadores ou suas organizações, assim como uma ou várias organizações de trabalhadores.

A Consolidação das Leis do Trabalho, em seu art. 611, caput, dispõe que a convenção coletiva é um acordo de caráter normativo, através do qual dois ou mais sindicatos representativos de categorias profissionais e econômicas convencionam condições de trabalho aplicáveis às relações individuais de trabalho.

No Brasil, a convenção coletiva de trabalho foi instituída pelo Decreto n 21.761/1932, com base na lei francesa de 1919. A Constituição Federal Brasileira de 1934 foi a primeira a reconhecer as convenções. Já a Constituição de 1937 adotou a expressão "contrato coletivo", em que somente as associações legalmente reconhecidas pelo Estado detinham o poder de negociação. Essa mesma denominação foi utilizada pela CLT (arts. 611 e 612), e só foi modificada para "convenção coletiva" de trabalho em 1967, através do Decreto-lei nº 229.

Conforme entendimento de Nascimento (2004, p. 1121), as alterações na denominação explicam-se em razão de que:

Optou-se, na época, por contrato no lugar de convenção para salientar a natureza jurídica contratual do instituto, daí sua aplicação unicamente aos associados das entidades pactuantes, sem prejuízo, no entanto, de, por ato ministerial, operar-se a sua extensão a toda a categoria, incluindo, neste caso, sócios e não sócios do sindicato. Como se vê, a palavra contrato tinha uma conotação civilista, enquanto o vocábulo convenção surgiu em razão do efeito erga omnes das cláusulas, entendendo-se por tal a sua aplicação não apenas a associados das entidades sindicais mas a toda a categoria (grifo do autor).

Por sua vez, a Lei n8.542, de 23 de dezembro de 1992, referente à política nacional de salários mínimos, instituiu o contrato coletivo de trabalho, conforme previsto em seu art. $1^{\circ}, \$ 1^{\circ}$ e $\$ 2^{\circ}$ :

Art. $1^{\circ}$ A política nacional de salários, respeitado o princípio da irredutibilidade, tem por fundamento a livre negociação coletiva e reger-se-á pelas normas estabelecidas nesta lei.

$\$ 1^{\circ}$ As cláusulas dos acordos, convençẽes ou contratos coletivos de trabalho integram os contrates individuais de trabalho e somente poderão ser reduzidas ou suprimidas por posterior acordo, convenção ou contrato coletivo de trabalhe. (Revogado pela Lei 10.192, de 14.2.2001)

$\$ 2^{\circ}$ As condiçẽes de trabalho, bem como as cláusulas salariais, inclusive os aumentes reais, ganhos de produtividade do trabalho e pisos salariais proporcionais à extensão e à complexidade do trabalho, serão fixados em contrato, convenção ou acordo coletivo de trabalho, laudo arbitral ou sentença normativa, observalas dentre outros fatores, a produtividade e a lucratividade do setor ou da empresa. (Revogado pela Lei 10.192, de 14.2.2001)

Posteriormente, a Medida Provisória no 1.675, de 25 de setembro de 1998, revogou os $\$ \$ 1^{\circ} \mathrm{e} 2^{\circ}$ da Lei no $8.542 / 92$. 
Nascimento (2004, p. 1122) entende ser necessária mais uma categoria de negociação coletiva, ficando composta por três instrumentos normativos: "o acordo coletivo aplicável aos trabalhadores da empresa, a convenção coletiva de trabalho, que é o vínculo em nível de categoria econômica e profissional, e o contrato coletivo de trabalho, de âmbito nacional." Assim como o autor supracitado, a Recomendação no 163, II, 4.1, referente a promoção da negociação coletiva, da OIT, ratificada pelo Brasil, permite que a negociação coletiva seja admitida em todos os níveis de estabelecimentos, de empresas, de ramo de atividade, de indústria, regional ou nacional.

O conteúdo da negociação pode ser de caráter obrigacional ou normativo. O primeiro gera direitos e deveres entre as partes da negociação. O segundo reflete nas condições de trabalho, devendo ser consideradas nos contratos individuais de trabalho, a exemplo dos reajustes salariais (MARTINS, 2001, p. 132).

Nos termos do art. $611, \mathbb{S} 1^{\circ}$, da CLT, o acordo coletivo é o negócio jurídico entre sindicato de trabalhadores e uma ou mais de uma empresa em que são resolvidos conflitos de interesse.

Segundo Martins (2001, p. 128), tanto as convenções quanto os acordos coletivos servem para determinar condições de trabalho e regras obrigatórias às partes envolvidas, porém a diferença está nos sujeitos: "enquanto na convenção coletiva os sujeitos são os sindicatos de trabalhadores e de empregadores, o acordo coletivo envolve apenas o sindicato de empregados e a empresa ou empresas interessadas". Para o autor, a convenção coletiva tem aplicabilidade para a categoria. $\mathrm{O}$ acordo coletivo vale para os empregados da empresa ou empresas que fizeram parte do acordo.

A Recomendação no91, aprovada na 34a Sessão da Conferência da OIT em 1951, define acordo coletivo assim:

Para efeitos da presente recomendação, o termo acordos colectivos significa que todos os acordos por escrito sobre as condições de trabalho e termos de trabalho celebrado entre um empregador, um grupo de empregadores ou uma ou mais organizações de empregadores, por um lado, e um ou organizações mais representativas dos trabalhadores ou, na ausência de tais organizações, os representantes dos trabalhadores devidamente eleitos e autorizados por eles de acordo com as leis e regulamentos nacionais, por outro (grifo do autor).

Por sua vez, Delgado (2013, p. 1413) define acordo coletivo de trabalho com base no texto da CLT, como um:

[...] pacto de caráter normativo pelo qual um sindicato representativo de certa categoria profissional e uma ou mais empresas da correspondente categoria econômica estipulam condições de trabalho aplicáveis, no âmbito das respectivas empresas, às relações individuais de trabalho.

Os acordos coletivos são aplicáveis apenas às empresas e aos trabalhadores envolvidos, designados acordos de vontades, mais limitados do que as convenções coletivas (DELGADO, 2013, p. 1413).

Em países como o México, Cuba, Guatemala, Costa Rica e República Dominicana, os sindicatos 
possuem legitimidade exclusiva para negociar. Diferente de outros países como o Chile e Venezuela, nos quais se permite que as negociações sejam feitas por um grupo de trabalhadores, em nosso país, a legitimidade é apenas dos sindicatos e das empresas (MARTINS, 2001, p. 133).

Na França, Países Baixos, Finlândia, Áustria, Suécia, Bélgica, Luxemburgo, Grécia e Portugal, somente os sindicatos podem ser sujeitos de um contrato coletivo e acaso entes não sindicais ou mesmo comissões de trabalhadores forem partes nas negociações, estas deverão serem submetidas à homologação do sindicato (NASCIMENTO, 2003, p. 312).

A Recomendação n91, II, 2, 1, da OIT, na mesma linha, admite que vários sujeitos podem ser legitimados em uma negociação coletiva:

[...] um empregador, um grupo de empregadores ou uma ou mais organizações de empregadores, por um lado, e um ou organizações mais representativas dos trabalhadores ou, na ausência de tais organizações, os representantes dos trabalhadores devidamente eleitos e autorizados por eles de acordo com as leis e regulamentos nacionais, por outro.

A legislação brasileira determina que os trabalhadores serão representados pelo sindicato profissional, enquanto que os empregadores podem contratar diretamente, ou por meio de representação sindical, nos termos da CLT, art. 611 , capute $\$ 1^{\circ}$.

Os sindicatos e as empresas, em relação ao acordo coletivo, não são os únicos legitimados. Conforme art. 61 , capute $\$ 1^{\circ}$, da CLT, é possível a existência de categorias que não estão organizadas em sindicato:

$\$ 2^{\circ}$ As Federações e, na falta desta, as Confederações representativas de categorias econômicas ou profissionais poderão celebrar convenções coletivas de trabalho para reger as relações das categorias a elas vinculadas, inorganizadas em Sindicatos, no âmbito de suas representações.

Segundo Brito Filho (2009, p. 176), no Brasil, as centrais sindicais não possuem legitimidade para negociar pelo fato de não serem consideradas entidades sindicais, assim como as comissões de empresa.

O ordenamento jurídico brasileiro, nos termos do art. 617 da CLT, trata da possibilidade de os trabalhadores celebrarem diretamente acordo coletivo de trabalho, quando aos sindicatos de sua representação não manifestam interesse pela iniciativa dos trabalhadores em fazer a negociação. Assim, o sindicato representativo da categoria profissional tem prazo de oito dias para assumir a direção da negociação. Ultrapassado o prazo sem a manifestação do sindicato, os interessados podem dar conhecimento à Federação, ou, na sua falta, à Confederação, com igual prazo para se manifestar. Se, ainda assim, não houver manifestação para agir frente à negociação, aí sim os interessados podem agir diretamente.

Conforme Delgado (2013, p. 1419), a jurisprudência do Supremo Tribunal Federal e do Tribunal Superior do Trabalho não consideram constitucional a negociação coletiva feita entre sindicatos de servidores públicos celetistas e respectivos entes públicos empregadores, mesmo tendo o Brasil ratificado a Convenção no 
154 da OIT, que trata do incentivo à negociação coletiva, inclusive sobre a administração publica (art. 1º, III).

Por meio da negociação coletiva pode ocorrer alteração em desfavor dos trabalhadores, nos termos do art. 7º, VI (redução de salário por acordo coletivo) e XVIII (compensação de jornada de trabalho), da Constituição Federal, e Lei no 9.601/98, sobre contrato de trabalho por tempo determinado. Essas são hipóteses em que a legislação brasileira permite a flexibilização do Direito do Trabalho, segundo Brito Filho (2009, p. 182183), e afirma que essa flexibilização é importante para o fortalecimento da autonomia privada coletiva em relação ao ordenamento jurídico do Estado.

A flexibilização dos direitos trabalhistas seria consequência das transformações do mundo do trabalho advindas do desenvolvimento da economia, das transformações tecnológicas e estruturais que se iniciaram na Europa, a partir da década de 60. Por meio da flexibilização, sustenta-se que seria possível um avanço das soluções negociadas como forma de solução de conflitos, e um meio de regular as condições de trabalho segundo as necessidades atuais.

Entretanto, não parece ser o momento mais oportuno para implantar, no Brasil, a flexibilização, em virtude de o sistema organizacional sindical ser o da unicidade, e, em razão disso, as entidades sindicais existentes atualmente são fracas pela ausência de concorrência entre si e não garantem concreta proteção ao trabalhador. $\mathrm{Na}$ prática, a flexibilização seria uma ferramenta utilizada contra os trabalhadores e favorável aos empregadores (BRITO FILHO, 2009, p. 183).

As cláusulas das convenções coletivas, segundo classificação de Russomano (2000, p. 179-180), estão divididas em obrigacionais e facultativas. As cláusulas obrigacionais são aquelas em que os assuntos que devem constar em uma convenção coletiva, como o tempo de duração ou vigência do convênio. Já as cláusulas facultativas são compreendidas como as acordadas livremente entre as partes.

Martins (2001, p. 132) entende que o conteúdo da negociação deve ser obrigacional e normativo. O obrigacional gera direitos e deveres entre as partes, enquanto que o conteúdo normativo envolve as condições de trabalho que devem ser observadas nos contratos individuais de trabalho.

A convenção e o acordo coletivo devem seguir um rito de formalidade, segundo Delgado (2013, p. 1421): "necessariamente lançados por escrito, submetidos a divulgação pública razoável, têm os próprios procedimentos para sua concepção e concretização subordinados a ritos e exigências de relativa complexidade".

O art. 612 da CLT determina que a celebração da convenção ou acordo coletivo de trabalho deve cumprir os seguintes requisitos:

Art. 612 - Os Sindicatos só poderão celebrar Convenções ou Acordos Coletivos de Trabalho, por deliberação de Assembléia Geral especialmente convocada para êsse fim, consoante o disposto nos respectivos Estatutos, dependendo a validade da mesma do comparecimento e votação, em primeira convocação, de 2/3 (dois terços) dos associados 
da entidade, se se tratar de Convenção, e dos interessados, no caso de Acôrdo, e, em segunda, de $1 / 3$ (um têrço) dos mesmos.

Parágrafo único. $\mathrm{O}$ "quorum" de comparecimento e votação será de 1/8 (um oitavo) dos associados em segunda convocação, nas entidades sindicais que tenham mais de 5.000 (cinco mil) associados.

Nos termos do art. 614, caput, $\$ \$ 1^{\circ}, 2^{\circ}$ e $3^{\circ}$, da CLT, as partes deverão promover depósito de uma via no Departamento Nacional do Trabalho, dentro do prazo de oito dias da assinatura do acordo ou convenção, para fins de registro e arquivo, bem como afixação das vias nas sedes dos sindicatos e estabelecimentos das empresas no prazo de cinco dias da data de depósito. Além disso, entram em vigor três dias após a data de sua entrega junto a esse órgão, e a convenção e o acordo não podem ter duração maior de dois anos.

Em relação ao instrumento coletivo judicial, há a ação de dissídio coletivo, que se enquadra na forma heterocompositiva de solução de conflitos na esfera coletiva.

A heterocomposição é integrada pela arbitragem e pela jurisdição, sendo que esta pesquisa ater-se-á apenas à jurisdição, mais utilizada pelo Brasil. Conforme Nascimento (2004, p. 1136), a "heterocomposição é a forma de composição de conflito por meio de uma fonte ou de um poder supra partes, por estas admitido, ou imposto pela ordem jurídica”.

A forma de solução jurisdicional de conflitos coletivos de trabalho está classificada em dois tipos: de natureza jurídica e de natureza econômica. A primeira é solucionada de forma semelhante a dos conflitos individuais, pela coincidência entre os procedimentos (reclamação trabalhista, ação de cumprimento, ação civil publica e ação anulatória de cláusulas convencionais). A segunda envolve ação específica: o dissídio coletivo. $\mathrm{O}$ art. 114, $\$ 2^{\circ}$, da Constituição Federal prevê a competência material da Justiça do Trabalho para essas demandas:

$[. ..] \S 2^{\circ}$ Recusando-se qualquer das partes à negociação coletiva ou à arbitragem, é facultado às mesmas, de comum acordo, ajuizar dissídio coletivo de natureza econômica, podendo a Justiça do Trabalho decidir o conflito, respeitadas as disposições mínimas legais de proteção ao trabalho, bem como as convencionadas anteriormente. [...]

Segundo Nascimento (2003, p. 290), a solução dos conflitos na esfera jurisdicional tem suas vantagens e desvantagens. As vantagens são constituídas pela maior segurança das decisões judiciais, maior isonomia dos julgados em detrimento da soma de todos os interesses do litígio, a imparcialidade, a facilidade na execução das decisões e a aplicação de meios coercitivos em caso de descumprimento. As desvantagens encontram respaldo em eventual discordância entre critérios do órgão jurisdicional e o programa econômico traçado pelo Estado.

Brito Filho faz uma crítica sobre o meio de solução de conflitos coletivos de trabalho de natureza econômica. Para o autor, esse meio é responsável pelos sindicatos brasileiros terem pouco poder de representatividade. A solução jurisdicional de conflitos coletivos desestimula a negociação ou demais formas de solução de conflitos, porque entes sindicais profissionais não possuem poder para movimentar a categoria que 
representam, "o que enfraquece ainda mais, em círculo vicioso que só traz prejuízos para os trabalhadores"(2009, p. 238).

Para Delgado (2013, p. 1334), “a figura da sentença normativa tem sido muito criticada, contemporaneamente, por traduzir fórmula de desmesurada intervenção do Estado na gestão coletiva dos conflitos trabalhistas." Segundo o autor, é em razão dessas críticas que, segundo a Constituição Federal, em seu art. $114, \S 2^{\circ}$, se viabilizou a propositura de dissídio coletivo apenas quando há recusa por qualquer das partes à negociação coletiva ou à arbitragem. Posteriormente, em 2004, com a Emenda Constitucional n. 45, criou-se nova restrição ao ajuizamento do dissídio coletivo de natureza econômica, inserindo a expressão "de comum acordo", de modo que, para o ajuizamento de dissídio coletivo, além de haver a recusa por uma das partes à negociação coletiva ou à arbitragem, devem estar em comum acordo. Ainda para Delgado, essa alteração "diminuiu significativamente o papel do dissídio coletivo na ordem jurídica, social e econômica do país".

Nesse contexto, conclui-se que, com a perda da importância do dissídio coletivo, acentua-se ainda mais a valorização da negociação coletiva trabalhista.

A jurisprudência trabalhista também tem se ajustado, como, por exemplo, a nova redação dada a Súmula 277 do TST, por meio do Precedente Normativo n 120 do TST, sobre a duração da sentença normativa. Com base no entendimento de Delgado (2013, p. 1134-1135), essa nova orientação reforça o princípio da equidade dos contratantes coletivos trabalhistas e estimula a negociação coletiva. Com essas mudanças, a única alternativa é alterar as cláusulas de uma convenção ou acordo coletivo de trabalho que não sejam mais de interesse das partes, ou se tornaram inadequadas ao longo das transformações sociais e econômicas.

Após contextualizado o mundo do trabalho contemporâneo com os impactos do fenômeno da globalização e explicitados os principais aspectos da representação sindical e seus instrumentos coletivos, pode-se voltar a atenção para as perspectivas que se abrem para o futuro do sindicalismo.

\section{AS TENDÊNCIAS DO SINDICALISMO NO NOVO CONTEXTO}

É inegável que o mundo do trabalho vem se transformando ao longo dos tempos, principalmente nos países capitalistas avançados, pelas inovações tecnológicas. Segundo Pereira (2004, p. 42), em detrimento dessas transformações, constatou-se um grande aumento na "desproletarização do trabalho industrial e fabril", ou seja, uma considerável diminuição dos trabalhadores da classe operária. Também surgiram várias formas de fragmentação do trabalho, como terceirização, subcontratação e precarização do trabalho, culminando no aumento do número de trabalhadores informais. 
Com a atual supremacia do capital financeiro e as ferramentas de telemática no contexto de globalização, há não apenas a instantânea circulação da informação mas também dos fluxos de capitais. Com isso, os Estados ficam praticamente sem fronteiras quando se trata da movimentação econômica, particularmente de capitais financeiros.

Assim, como a lógica da competitividade é importante para as conquistas de mercado, movidas quase que exclusivamente pela sua racionalidade instrumental puramente econômica (menos custos e mais lucros), prevalece o discurso de que as empresas que se tornam menos competitivas caminham para a falência e geram desemprego (PEREIRA, 2001, p. 148). Com isso, a precarização dos direitos sociais em geral, mas particularmente os trabalhistas, vira uma moeda importante no discurso e na prática das corporações transnacionais. Note-se, por oportuno, que as corporações não agem apenas em busca de menores custos sociais, mas também menores custos tributários e ainda ambientais, seja por legislações mais brandas aos seus interesses, seja mesmo por legislações na prática menos efetivas, e, em todos esses aspectos, atingem diretamente as políticas públicas estatais mais nucleares.

Retomando o exemplo brasileiro, cabe lembrar que o sindicalismo nacional segue o modelo criado por Getúlio Vargas, ou o modelo sindical tido como "reserva de mercado" que não precisava lutar para existir. Os sindicatos mantêm-se com o imposto sindical obrigatório, onde todos, sem exceção, devem contribuir. Desse modo, a quantidade de trabalhadores associados aos sindicatos foi reduzida drasticamente, porque os sindicatos não precisam da associação ou da participação efetiva dos trabalhadores para existir, e, em verdade, sequer precisam celebrar acordos ou convenções para receberem sua contrapartida automática e periódica de arrecadação. De certa forma, o sindicalismo brasileiro é subsidiado pelo Estado, e, como apontam vários críticos, uma das principais maneiras de fazer com que o sindicato de hoje realmente defenda os interesses dos trabalhadores é "destruir essa estrutura sindical brasileira" (MEDEIROS, 1990, p. 126-127).

Se o Brasil adotasse um regime de efetiva liberdade sindical, mais trabalhadores se engajariam num movimento em busca de melhores condições de vida, ao passo que o sindicato como representante da classe dos trabalhadores deve atuar com mais intensidade para não ser extinto. Para alcançar esse objetivo, o sindicato deve ter liberdade e assim defender seus representados. Essa liberdade, ainda não atingida pelo Brasil, depende de uma organização sindical desvinculada do Estado, o que só é possível através do pluralismo sindical (OLIVEIRA, 2006, p. 135).

Embora essa situação seja evidente nas categorias profissionais (de trabalhadores), ela não é muito diferente nas categorias econômicas (de empregadores). Na prática, os sindicatos de ambas as categorias auferem o mesmo tipo de contribuição por fonte de custeio similar, que independe da qualidade ou quantidade de sua 
atuação, ou mesmo da associação e participação dos representados.

Pereira (2001, p. 152-154) entende que os sindicatos da sociedade contemporânea devem acompanhar as transformações no mundo do trabalho, em relação à organização de produção capitalista, frente às novas formas de relações de trabalho, como a terceirização. Para o autor, os sindicatos devem se assumir como "órgão de luta política e adotar uma estratégia de ruptura com o atual estado das coisas", o que significa lutar em defesa da cidadania e não apenas de lutas econômicas reivindicativas imediatas. Pereira defende, ainda, a "internacionalização do movimento sindical" como o único meio de encadear um eficaz combate frente à crise sindical de hoje.

Os sindicatos são entidades com capacidade para criar "um novo projeto para a sociedade onde a cidadania esteja identificada com a emancipação política e social do trabalhador, no qual o sindicato assuma um papel crítico a interagir sobre os destinos da sociedade com outros segmentos populares rumo à democracia [...]", com base na liberdade e na solidariedade (PEREIRA, 2004, p. 70).

Não por acaso, e para o fortalecimento dos sindicatos em todo o mundo, a Organização Internacional do Trabalho defende uma liberdade sindical em relação aos direitos dos trabalhadores e dos empregadores, à criação e à adesão de entidades sindicais de sua livre escolha, sem nenhuma interferência. Ligada à liberdade sindical, está a negociação coletiva, que permite aos trabalhadores negociarem livremente com seus empregadores melhores condições de trabalho. A OIT considera esses direitos universais, devendo ser aplicados, também, aos trabalhadores de economia informal.

Para a OIT, a liberdade sindical é de suma importância, uma vez que garante aos trabalhadores e empregadores a possibilidade de defenderem seus interesses, a proteção contra a discriminação e o assédio, e, inclusive, contribui com a democracia e com o desenvolvimento dos países aderentes. A liberdade sindical abre portas para a conquista de direitos e princípios fundamentais no trabalho.

Conforme o site da Organização Internacional do Trabalho no Brasil, na publicação "A liberdade sindical e a liberdade de associação são um direito humano fundamental, diz a OIT", datada de 26 de junho de 2008, que trata do Relatório Global "A liberdade de associação e a liberdade sindical na prática: lições aprendidas", há uma visão geral da aplicação e do cumprimento efetivo dos princípios e direitos universais relativos à liberdade de associação, liberdade sindical e negociação coletiva.

Segundo a publicação, até 2007, de um total de 182 Estados-Membros, 148 haviam ratificado a Convenção n87 e 158 haviam ratificado a Convenção n98. O segundo relato da OIT é preocupante, pelo fato de a Convenção n87 ter se tornado a menos ratificada das oito Convenções fundamentais. O Brasil é um dos países que ainda não ratificou a Convenção no87, sobre liberdade sindical e direito de sindicalização, considerada 
uma das mais importantes normativas da OIT.

Conforme entendimento da OIT, todos os trabalhadores e empregadores possuem o direito de criar as organizações que julgarem adequadas e de associar-se a elas, com a finalidade de promover e defender seus interesses e de celebrar negociações coletivas com a outra parte, de forma livre e sem interferência de umas sobre as outras, inclusive do Estado.

A liberdade sindical, pois, é considerada pela OIT um direito humano fundamental que, juntamente com a liberdade de associação e com o direito de negociação coletiva, representam um valor central da OIT.

Não por acaso, e dessa perspectiva, os direitos de sindicalização e de negociação coletiva ajudam no desenvolvimento da democracia, na administração do mercado de trabalho e na promoção de melhores condições de trabalho para os próprios trabalhadores, e, por isso, devem ser amplamente garantidos.

\section{CONSIDERAÇÕES FINAIS}

Na sociedade contemporânea, totalmente influenciada pelo fenômeno da globalização, observa-se que o mundo do trabalho vem sofrendo grandes transformações.

Uma ocorreu de forma gradativa em todos os países onde se fez presente o desenvolvimento industrial:a reestruturação produtiva. Apesar de possuírem características próprias, todas essas transformações apresentam em comum o objetivo de maximizar lucros e ampliar a acumulação do capital, por meio inclusive do aumento da apropriação da mais-valia e da produtividade do trabalho humano contratado.

Tudo isso acaba influenciando significativamente no mundo do trabalho, como se pode perceber, com os ideais neoliberais que se tentam implantar, interligados com os movimentos de flexibilização dos direitos trabalhistas. Contudo, essa flexibilização, em um país como o Brasil, onde o sindicalismo está atrelado ao Estado, enfraquecido e sem a participação legítima dos trabalhadores, parece ser inviável e contraproducente.

Por outro lado, observa-se que as negociações coletivas estão ganhando mais força e destaque no Direito Trabalhista do mundo e no ordenamento jurídico nacional, em razão do fenômeno da globalização, no qual as normas jurídicas emanadas do Estado não conseguem acompanhar o desenvolvimento da economia, bem como expressar de forma efetiva os interesses dos trabalhadores e empregadores.Dadas as peculiaridades que envolvem o desenvolvimento de determinada atividade, tornam-se imprescindíveis os instrumentos negociais para tornar efetivos os direitos das categorias específicas nesse contexto.

Vive-se hoje a supremacia do capitalismo avançado, através da globalização e imposição do livre comércio, sem a interferência dos Estados-Nação. 
A competitividade é a porta principal para a conquista dos mercados econômicos, passando por cima das normas estatais, e principalmente, das normas que regulam as relações de trabalho em nome de maior produtividade e lucratividade, culminado na precarização do mundo do trabalho, no desemprego e na exclusão social, que, em última instância, comprometem os valores básicos da dignidade humana.

Conclui-se que, na sociedade contemporânea, os sindicatos devem acompanhar as transformações econômicas, preocupando-se com as profundas mudanças do mundo do trabalho. Para tanto, as entidades sindicais devem assumir o seu papel como órgãos de luta política e social, em prol da defesa da cidadania.

Por isso, um dos meios para alcançar esses objetivos é concretizar a democracia através da plena liberdade sindical, tida como direito universal pela Organização Internacional do Trabalho. Assim como já o fazem empresas transnacionais, os sindicatos devem se mobilizar globalmente, fechando acordos em nível global para a proteção dos trabalhadores, e, principalmente, assim como a OIT, defender a liberdade de associação e a pluralidade sindical, uma vez que a liberdade sindical abre portas para a conquista de direitos e princípios fundamentais no mundo do trabalho, que, em última instância, são da própria cidadania.

\title{
UNIONISM CHALLENGES IN GLOBALIZED SOCIETY
}

\begin{abstract}
This study aims to understand challenges of trade unions role in contemporary society in globalization era. It analyzes globalization phenomenon and its impact on labour relations, with deep changes of advanced capitalism in international society. Production and labour organization models have hugely changed world wide, creating an uneven reality. In addition, the study investigates as an example trade unions representation and their collective instruments in Brazilian law. Trade union model in Brazil does not allow union plurality and remains unchanged over the past 70 years, and uneven to major economic and social changes of the early twenty-first century. The article finally also studies trends in the role of unions in contemporary global society. Unions are important actors in the affirmation of political, social, and economic rights of categories they represent. The main conclusion is that the more effective action of unions in a globalized society faces the construction of a new paradigm, based on democracy, pluralism, and freedom of association, recognized as universal rights by the International Labour Organization. The methodology used in this work is based on deductive method in qualitative research grounded on bibliographic sources.
\end{abstract}

Keywords: Unions; Globalization; International Society.

\section{REFERENCIAS}

ALBUQUERQUE, Ana Paula Freitas de. "O mundo do trabalho na era da globalização". In: ALBUQUERQUE, 
Ana Paula Freitas de(Org.). Estudos de direito do trabalho e processo do trabalho. Passo Fundo: IMED, 2006, p.21-57.

ALVES, Giovanni. Dimensões da Reestruturação Produtiva, ensaios de sociologia do trabalho. 2 ed. Brasil: Práxis, 2007.

ANTUNES, Ricardo. Adeus ao trabalho? Ensaio sobre as metamorfoses e a centralidade do mundo do trabalho. 11 ed. São Paulo: Cortez, 2006.

ANTUNES, Ricardo. Os sentidos do trabalho. Ensaio sobre a afirmação e a negação do trabalho. São Paulo: Boi tempo Editorial, 2005.

BARBOSA, Alexandre de Freitas. O mundo globalizado: política, sociedade e economia. 2. ed. São Paulo: Contexto, 2003.

BOITO JUNIOR, Armando. Hegemonia neoliberal e sindicalismo no Brasil. Crítica Marxista. Disponível em: <http://www.ifch.unicamp.br/criticamarxista/arquivos_biblioteca/artigo260artigo 193_Boito.pdf> Acesso em: 14 de setembro de 2015.

BRASIL. Constituição da República Federativa do Brasil (1988). Disponível em: <http://www.planalto.gov.br/ccivil_03/constituicao/constituicaocompilado.htm> Acesso em: 21 de agosto de 2013.

BRASIL. Decreto n. 21.761, de 23 de agosto de 1932. Institui a convenção coletiva de trabalho. Disponível em: $<$ http://legis.senado.gov.br/legislacao/ListaNormas.action?numero=21761\&tipo_norma=DEC\&data=193208 23\&link=s> Acesso em: 15 de setembro de 2014.

BRASIL. Decreto Lei n. 229, de 28 de fevereiro de 1967. Altera dispositivos da Consolidação das Leis do Trabalho, aprovada pelo Decreto-lei no 5.452, de $1^{\circ}$ de maio de 1943, e dá outras providencias. Disponível em: <http://www.planalto.gov.br/ccivil_03/decreto-lei/del0229.htm> Acesso em: 15 de setembro de 2014.

BRASIL. Decreto Lei n. 5.452, de $1^{\circ}$ de maio de 1943. Aprova a Consolidação das Leis do Trabalho. Disponível em: <http:// www.planalto.gov.br/Ccivil/Decreto-Lei/Del1402.htm> Acesso em: 21 de agosto de 2013.

BRASIL. Lei n 8.542, de 23 de dezembro de 1992. Dispõe sobre a política nacional de salários. Disponível em: <http://www.planalto.gov.br/ccivil_03/leis/18542.htm> Acesso em: 15 de setembro de 2014 .

BRASIL. Proposta de Emenda à Constituição n. 369/2005. Disponível em: < http://www.camara.gov.br/proposicoesWeb/prop_mostrarintegra?codteor=280671\&filename=PEC+369/20 05> Acesso em: 09 de setembro de 2014.

BRITO FILHO, José Claudio Monteiro de. Direito sindical: análise do modelo brasileiro de relações coletivas de trabalho à luz do direito comparado e da doutrina da OIT - proposta de inserção da comissão de empresa. 3 ed. São Paulo: LTr, 2009.

DELGADO, Mauricio Godinho. Curso de direito do trabalho. 12 ed. São Paulo: LTr, 2013. 
MARTINS, Sergio Pinto. O pluralismo do direito do trabalho. São Paulo : Atlas, 2001.

MEDEIROS, Luiz Antonio de. "Visão Europeia". O futuro do sindicalismo no Brasil: o diálogo social. São Paulo: Pioneira, 1990, p. 126-130.

NASCIMENTO, Amauri Mascaro. Curso de direito do trabalho: história e teoria geral do direito do trabalho, relações individuais e coletivas do trabalho. 19 ed. rev. e atual. São Paulo: Saraiva, 2004.

NASCIMENTO, Amauri Mascaro. Compêndio de direito sindical. São Paulo: LTr, 2003.

OLIVEIRA, Olga Maria Boschi Aguiar. "O Sindicalismo brasileiro e as práticas anti-sindicais". Estudos de direito do trabalho e processo do trabalho. Passo Fundo - RS: IMED, 2006, p.29-48.

OLSSON, Giovanni. "A sociedade internacional contemporânea e o papel dos atores globais no mundo do trabalho". Diálogos entre o direito do trabalho e o direito constitucional. São Paulo: Saraiva, 2014, p.589-623.

ORGANIZAÇÃO INTERNACIONAL DO TRABALHO. Convenções ratificadas pelo Brasil. Disponível em: <http://www.oitbrasil.org.br/convention>. Acesso em: 15 de abril de 2014.

ORGANIZAÇÃO INTERNACIONAL DO TRABALHO. Convenções. Disponível em: <http://www.lo.org/dyn/normlex/en/f?p=NORMLEXPUB:12000:0::NO:::> Acesso em: 15 de abril de 2014.

ORGANIZAÇÃO INTERNACIONAL DO TRABALHO. A liberdade sindical e a liberdade de associação são um direito humano fundamental, diz a OIT. Disponível em: $<$ http://www.oitbrasil.org.br/content/liberdade-sindical-e-liberdade-de-associa\%C3\%A7\%C3\%A3os\%C3\%A3o-um-direito-humano-fundamental-diz-oit> Acesso em: 28 de setembro de 2014.

PEREIRA, António Garcia. Globalização: novos rumos no mundo do trabalho. Florianópolis: UFSC/SOCIUS, 2001.

PEREIRA, Josecleto Costa de Almeida. Globalização do trabalho: desafios e perspectivas. Curitiba: Juruá, 2004.

POCHMANN, Marcio. O trabalho sob fogo cruzado: exclusão, desemprego e precarização no final do século. São Paulo: Contexto, 2002.

RUSSOMANO, Mozart Victor. Princípios gerais de direito sindical. 2 ed. ampliada e atualizada. Rio de Janeiro: Forense, 2000.

SENE, Eustáquio de. Globalização e espaço geográfico. São Paulo: Contexto, 2003.

Trabalho enviado em 14 de outubro de 2017.

Aceito em 18 de janeiro de 2018. 